\title{
Analysis of Demographic Pressure on Nature
}

\author{
Didenko N.I. \\ International Graduate School of Management \\ Peter the Great St. Petersburg Polytechnic University \\ St. Petersburg, Russia \\ didenko.nikolay@mail.ru
}

\author{
Skripnuk D. F. \\ International Graduate School of Management \\ Peter the Great St. Petersburg Polytechnic University \\ St. Petersburg, Russia \\ djamilyas@mail.ru
}

\author{
Kikkas K. N. \\ International Graduate School of Management \\ Peter the Great St. Petersburg Polytechnic University \\ St. Petersburg, Russia \\ xekikkas@gmail.com
}

\begin{abstract}
The article evaluates the demographic pressure on nature. Demographic pressure on nature means the development of anthropogenic factors, caused by an increase in population and, consequently, by increased production and growth of the agrosphere. Analysis of demographic pressure on nature includes the following procedures: forecasting the population growth; forecasting the necessary growth in production and the necessary growth of the agrosphere; prediction of anthropogenic pressure; analysis of the consequences of demographic pressure; analysis of the possibility of a stable and balanced development of the world economy in conditions of demographic pressure; technological, economic opportunities and the limits of production growth in conditions of demographic pressure; assessment of countries in terms of socio-demographic risk. The general principles and the scheme of the analysis and forecasting of demographic pressure are developed. The results of forecasting the growth of the population according to three scenarios - pessimistic, optimistic and average, are stated. Together with the growth of the population, humankind will face a need to increase production. The forecast of growth of consumption for one inhabitant of the USA up to 2050 is made. It is defined if it is necessary to increase manufacture in the world if the world consumption level will be like in the USA. For comparison, a realistic forecast for the growth of the total world domestic product was compiled. The article outlines the consequences of demographic pressure: social, economic and environmental. An estimation of countries in terms of convergence and divergence of indicators of social processes development in conditions of demographic pressure is shown.
\end{abstract}

Keywords-Population of the Earth; demographic pressure; sustainable development; forecasting the population growth; consequences of demographic pressure; convergence and divergence of social processes.

\section{INTRODUCTION}

The problem of uncontrolled population growth occupies the world community for over a hundred years. Various scientists put forward theories of demographic growth and thought about annually increasing demographic pressure [1-5]. Currently, this problem is becoming more urgent, since the growing demographic pressure can hamper the steady growth of the world economy. Recently, specialists concluded that the continuation of unrestrained economic growth on the existing technological base will lead humanity to a catastrophe which threatens its existence. This conclusion is based on a number of interrelated arguments. First, due to the population growth and increased production, in the near future the population may face a shortage of natural resources, which often serves as the basis for production activities. In addition, currently existing technologies are increasingly pushing the world to an ecological catastrophe. Third, in recent years, the problem of the gap in society, the aggravation of the problems of income inequality and poverty is becoming increasingly important. In such conditions, the need to develop and implement the concept of sustainable development for the entire world community became evident. However, one should not forget that at present, the development of the world economy takes place under conditions of demographic pressure, which must also be taken into account when proposing the principles of sustainable development.

"Demographic pressure" complicates not only the problem of income inequality and poverty, but also has a negative impact on the development process. For example, the rapid growth of population does not allow stabilizing the problem of unemployment, makes it difficult to solve the problems of education, health care, social security, and others. Thus, the purpose of this article is to evaluate the consequences of demographic pressure.

\section{OVERVIEW OF RESEARCH PROBLEMS}

Demographic pressure on nature is a multifaceted problem. The range of issues under consideration is very extensive. The main issue is the demographic development of the territories [6-8]. This is covered in the works of T.R. Malthus, A. Landry, S. P. Kapiza, A. Ya. Boyarsky, D. I. Valentej, A. Ya. Kvasha, V.A. Bashlachev and others. The question of the ultimate living space of human survival and the scientific and technological development of the agrosphere is important [9], [10]. Many aspects of this problem have been investigated by NA. Aghajanyan, V.G. Gorshkov, E.V. Girusov, V.I. Danilov - Danilyan, AA Zhuchenko, A.N. Kashtanov, V.P. Kaznacheev, V.I. Kushlin, V.D. Komarov, V.N. Lopatin, K.S. 
Losev, V.A. Los, N.M. Mamedov, E-V- Nikanorova, N.N. Moiseyev, S.V. Pirogov, R.S. Permyakov, I.G. Rodzianko, N.F. Reimers, AD Ursul, I.T. Frolov, I.M. Shabunina, A.S. Shilov, A.V. Yablokov, A.L. Yanshin and others.

Analysis of the influence of technogenic factors on nature is found in the works of V.A. Abakumov, M.A. Glazovskaya, V.G. Zaikanov, A.B. Khabarov, E.Yu. Bezuglaya, T.V. Zvonkova, N.I. Koronkevich, N.M. Chernavskaya and others. The conclusion from a survey of research on the problem of demographic pressure on nature is that this problem has become a global problem of the world economy.

\section{PRINCIPLES, Methods For PREDICTING DEMOGRAPHIC PRESSURE ON NATURE, DATABASE}

Analysis and forecast of demographic pressure on nature are based on the following provisions:

a) The forecasting model of the corresponding indicators is presented as the sum of the indicator and harmonics trends. To determine the trend indicator, linear function $y=a_{0}+a_{1} t$ was used. Deviations from trend $\Delta y(t)=y_{t}-y_{\text {trend }}$ are represented in the form of sinusoidal and cosine functions: $\Delta y(t)=A_{0}+A_{1} \cos \frac{2 \pi}{T_{1}} t+A_{2} \sin \frac{2 \pi}{T_{1}} t$,

where $A_{0}$ - absolute term, $A_{1}$ and $A_{2}$ - coefficients.

b) Chain rates of population growth for each year serve as a basis for determining three scenarios for population growth: average, optimistic and pessimistic.

c) The ratio of world consumption and total global GDP was taken as it has developed over the past 40 years [11].

d) Given that the world has a desire to consume as much as the inhabitants of developed countries do, the forecast of consumption growth was based on the consumption of the US citizen until 2050 and it determined how much it would be necessary to increase production in the world if everyone in the world consumed like in the US.

e) As predictive indicators, the growth in emissions of carbon monoxide $\left(\mathrm{CO}_{2}\right)$ and methane $\left(\mathrm{CH}_{4}\right)$ were chosen in order to study the growth of anthropogenic pressure caused by the growth of production.

f) The forecast of the necessary growth of the agrosphere, caused by population growth and assessment of the availability of this growth, was carried out in order to determin how much arable land should grow in order to produce the same volumes of agricultural products per person as at the current time.

g) To analyze the possible consequences of demographic pressure, the method of expert assessments was used.

h) The statistical database is the time series of data from 1960 to 2014. The following main sources of information were used: the database http://www.portal.euromonitor.com/; CIA website - https://www.cia.gov/; Official website of the International Monetary Fund - http://www.imf.org/; World Bank website http://date.worldbank.org/indicator/.

\section{RESULTS AND DISCUSSION}

\section{A. Prediction of population growth}

The population by the average scenario is determined based on the trend and harmonics. For the trend equation, the coefficient is $a_{0}=2832712646,34$. Value $R^{2}$ shows the proximity of the trend to the actual data, equals 0.999 , which indicates a strong proximity of the trend model to the actual data.

The forecast of the population according to the pessimistic scenario is also calculated based on the trend. To calculate the trend equation, the time period from 1963 to 1974 was chosen, during which the growth rates were the highest and exceeded $2 \%$ per year.

For the forecast of the population according to the optimistic scenario, the time period from 2000 to 2011 was chosen, during which the growth rates were the lowest and made up no more than $1.2 \%$ on average.

The results of the forecast are the world population will increase from 2.8 to 4 billion people. If the current trend continues, then by 2050 the world's population will grow to 10.065 billion people, according to the pessimistic forecast, the population will reach 11 billion people, and according to the optimistic forecast 9.8 billion people.

\section{B. Forecasting the necessary growth in production and the necessary growth of the agrosphere in conditions of population growth}

The results of forecasting the necessary growth in production are striking. For all the inhabitants of the Earth to consume as residents of the United States, the total world GDP should increase 83 times by 2050 with the average forecast of population growth, 81 times - with optimistic and 90 times with pessimistic forecast, which is very unlikely, as the world average growth rate should be over $17 \%$. According to the results obtained, the difference between the real forecast of the total world GDP and the forecast of the total world GDP, provided that all the inhabitants of the Earth consume as much as in the United States, is 4.5 times. It is not possible to overcome this difference due to the existence of technological and economic limits of production growth.

It is possible to estimate these limits by analyzing the growth rates of total world GDP. It is the rate of growth that speaks about the possibilities of technology. From 1962 to 2015 , the average annual growth rate of total world GDP was $8.18 \%$. Thus, the technologies existing in the world at the moment are not capable of providing an average annual rate of growth, much exceeding $8.18 \%$. If mankind decides to achieve by 2050 the total world GDP, in which everyone will consume as much as residents of the United States, then from 2011 the rate of growth should constantly exceed $200 \%$. 
Using the data of average, optimistic and pessimistic forecasts of population growth, an assessment of the possibilities of the agrosphere to feed the growing population of the planet was made, holding the ratio of 0.25 hectares of the per capita availability of arable land for man. The Committee on Agrarian Issues of the State Duma of the Russian Federation has deduced a norm of 0.3 hectares as a necessary volume of arable land for the production of food per person.

Based on the calculations, with an average forecast of population growth, it is necessary to increase the arable land to 2.5 billion hectares. That is, by 2050 the area of arable land should increase by 1.1 billion hectares. How can this increase occur? Deforestation will allow receiving an additional billion hectares of acreage, but these measures threaten the deterioration of the ecological situation, the loss of precious forest resources, as well as soil erosion [12]. There are areas of land unsuitable for agriculture, pastures and forests. To include these lands in agricultural production, expensive measures are necessary to increase soil fertility, artificial irrigation, etc. Therefore, these events are rather problematic.

Another option is to increase the fertility of already existing land [13], [14], [15]. This requires a variety of new fertilizers and machinery. Will mankind be able to advance in development in this area by 2050 and to increase the productivity of soils twice remains an issue.

Now one shall calculate how much it is necessary to increase the area of arable land in case of an optimistic and pessimistic forecast of population growth. With a pessimistic result of population growth, the agrosphere, namely the arable land area, should grow by 1.2 billion hectares, with an optimistic option by 0.98 billion hectares. With any forecast, the necessary growth of the agrosphere is significant.

\section{Forecasting the anthropogenic pressure}

Emissions of carbon monoxide $\left(\mathrm{CO}_{2}\right)$ and methane $\left(\mathrm{CH}_{4}\right)$ per one US dollar of manufactured products in the world were chosen as a predicted indicator of anthropogenic pressure [16], [17]. In accordance with the forecasting method, the average growth rates of emissions for the period are calculated, the difference between the mean value and the actual emissions is calculated, the cycles of the emission growth rate fluctuations relative to the average growth rate are determined.

According to the results obtained, it is possible to compile possible equations for the cycles of actual emissions of carbon monoxide $\left(\mathrm{CO}_{2}\right)$ and methane $\left(\mathrm{CH}_{4}\right)$.

$$
\begin{aligned}
& y_{1}(t)=0.52932 \cos \frac{2 \pi}{16.7} t+2.82263 \sin \frac{2 \pi}{16.7} t \\
& y_{2}(t)=1.6588 \cos \frac{2 \pi}{7.1} t-0.37171 \sin \frac{2 \pi}{7.1} t
\end{aligned}
$$

$$
y_{3}(t)=-1.24198 \cos \frac{2 \pi}{4.2} t+2.01325 \sin \frac{2 \pi}{4.2} t
$$

Thus, within 50 periods, 3 cycles of 16.7 years, 7 cycles of 7.1 years and 12 cycles of 4.2 years are possible.

The general equation of growth rates of $\mathrm{CO}_{2}$ emissions looks like:

$$
\begin{aligned}
& y(t)=94.11+0.52932 \cos \frac{2 \pi}{16.7} t+2.82263 \sin \frac{2 \pi}{16.7} t+ \\
& 1.6588 \cos \frac{2 \pi}{7.1} t-0.37171 \sin \frac{2 \pi}{7.1} t- \\
& 1.24198 \cos \frac{2 \pi}{4.2} t+2.011325 \sin \frac{2 \pi}{4.2} t
\end{aligned}
$$

Calculation of the forecast values for the period up to 2050 shows that the growth rate of emissions decreases year by year. Knowing the forecast of emission growth rates, emissions of carbon monoxide and methane in the future were determined using the production forecast built earlier. For calculations, the production growth forecast based on the scenario of average population growth was used.

According to calculations, despite the decrease in the growth rates of emissions, by 2050 the emissions will increase 2.7 times. The increase in production emissions is caused by population growth. Undoubtedly, the development of new technologies and methods of production will further reduce the growth rate of emissions; however, increasing production will not allow reducing pollution to any significant extent.

The above forecasts make one think about the possible consequences of population growth and, as a consequence, the growth of demographic pressure.

\section{Analysis of the effects of demographic pressure}

Possible consequences of demographic pressure were analysed.

Based on the analyses, conducted within the framework of the considered topic, the following interrelated consequences of demographic pressure are formulated:

1. Increased anthropogenic pressure on nature (i.e., increasing pollution of water and air);

2. Lack of fresh water associated with population growth;

3. Loss of land suitable for agriculture due to increased pollution levels;

4. Lack of food, associated with the reduction of arable land per person, caused by population growth;

5. Lack of food related to the limits of technological growth;

6. Lack of fuel and raw materials and energy resources, associated with population growth and the non-renewability of some resources;

7. Overpopulation of the countries of the South; 
8. Aggravation of poverty in overpopulated countries;

9. The aging of the population of the countries of the North, which by 2050 threatens a sharp decline in the population;

10. Even more uneven territorial distribution of the population, especially in developing countries.

The method of expert evaluations was used. In this analysis, five experts participated. The concordance coefficient, which is 0.17 , was calculated. The value of the concordance coefficient indicates the inconsistency of the opinions of experts.

In this case, it is clear that all the consequences of demographic pressure put forth have the same risk for a stable and balanced development of the world economy. This is due to the fact that demographic pressure carries a risk for all areas - a social, economic or environmental spheres. Moreover, all these consequences are interrelated and the onset of one entails the offensive of the third and fourth, and so on.

\section{E. Structure of production - distribution - consumption on the planet that meets the principles of justice}

At this stage in the development of the world economy, production and consumption are for the mostly concentrated in developed countries, in addition, the distribution of the created world gross product also occurs in favor of this group of countries [18]. In contrast, the world population distribution is directly opposite to the distribution of total world GDP. Proceeding from this, such a structure of production, distribution and consumption cannot satisfy the principles of justice.

In order to evaluate how the distribution takes place, the Lorentz curve is used in the analysis. The Lorenz curve is a graph showing the degree of inequality in the distribution of income in society, the degree of inequality in the distribution of wealth, the degree of inequality in obtaining power [19], [20]. If the Lorentz curve is used to demonstrate the degree of inequality in the distribution of income in a society, it will show the share of income falling on to different population groups formed on the basis of the amount of income that they receive. It is also possible, by analogy, to assess how evenly the gross domestic product produced and consumed in the world is distributed. In other words, to assess how far the distribution is from the uniform distribution. On the Lorentz curve, the bisector demonstrates an equal distribution of income. If there was an equal distribution of income in the society, the Lorentz curve would take the form of a straight line called the line of absolute equality, and, finally, if only one percent of the population received all income in the society, then on the graph this would be a vertical straight line called the Absolute inequality line.

The Lorenz curve is compiled according to the obtained data (Tab. 1) and estimates how evenly the distribution of total world GDP happens.
TABLE I. CALCULATION OF THE LORENTZ CURVE

\begin{tabular}{|c|c|c|c|c|c|}
\hline $\begin{array}{l}20-\% \\
\text { groups of } \\
\text { population }\end{array}$ & $\begin{array}{l}\text { Volume of } \\
\text { GDP of } \\
\text { population, } \\
\text { in \% of } \\
\text { WGP }\end{array}$ & $\begin{array}{l}\text { Share of } \\
\text { GDP as } \\
\text { cumulative } \\
\text { total, in \% }\end{array}$ & $\begin{array}{l}\text { Area of a } \\
\text { triangle }\end{array}$ & $\begin{array}{l}\text { Area of a } \\
\text { rectangle }\end{array}$ & $\begin{array}{l}\text { Total } \\
\text { area of } \\
\text { the } \\
\text { figure, } \mathrm{S}_{\mathrm{i}}\end{array}$ \\
\hline 20 & 3.5 & 3.5 & 35 & 0 & 35 \\
\hline 40 & 5.5 & 9 & 55 & 35 & 90 \\
\hline 60 & 8 & 17 & 80 & 90 & 170 \\
\hline 80 & 10.5 & 27.5 & 105 & 170 & 275 \\
\hline 100 & 72.5 & 100 & 725 & 275 & 1000 \\
\hline & & & & & 1570 \\
\hline
\end{tabular}
0.57 .

Based on this curve, the calculated Gini coefficient was

The decile coefficient was also calculated. The decile coefficient of income differentiation is the ratio of the total world GDP of the last and the first population groups. It shows by how many times the total world GDP $10 \%$ of the most well-off population exceeds the total world GDP $10 \%$ of the least well-off population. $72.5: 3.5=20.71$

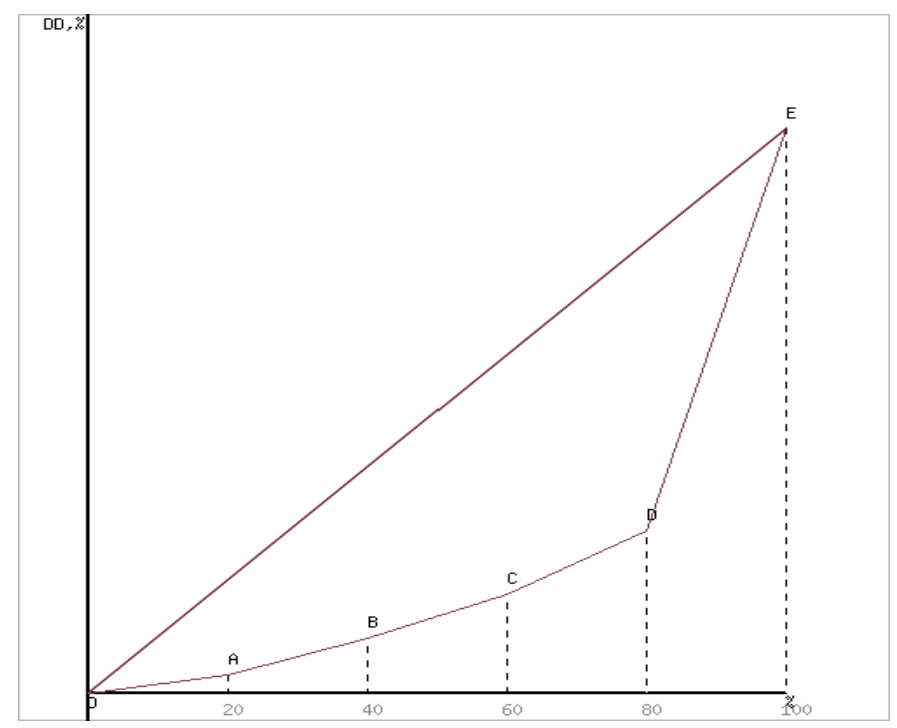

Fig. 1 - The Lorenz curve for the distribution of total world GDP

It is worth mentioning that the calculations show that in recent years, the $\mathrm{G} 7$ countries are reducing their share in world consumption and production, unlike the E7 countries, which increase this proportion. However, the ratio still remains much in favor of the former.

\section{F. Analysis of the convergence and divergence of indicators of social processes development in conditions of demographic pressure: HDI, consumption per person, electricity consumption per person}

To analyze the convergence and divergence of social processes, two methods were used in the research: $\sigma$ convergence and absolute $\beta$-convergence [21], [22].

Convergence $\sigma$ is valid if the dispersion of the indicator for a group of countries in time is reduced. In other words, if $\sigma_{j+\Delta j}<\sigma_{j}\left(\sigma_{j}\right.$ - a variance indicator $)$, then the hypothesis is 
valid. The coefficient of variation is used as the variance index. The hypothesis of testing the absolute $\beta$-convergence implies a negative statistical relationship between the growth rate of the indicator and its initial level. The pairwise regression dependence of the growth rate of the indicator and the initial level of this indicator is evaluated. For the analysis of convergence, one needs to find the following regression equation, that is, to determine the coefficients $\beta_{0}, \beta_{1}$ :

$$
\log T \sqrt[T]{\prod_{t=0}^{T} \frac{x_{t}}{x_{t-1}}} \cdot 100=\beta_{0}+\beta_{1} \log x_{t_{0}}
$$

where $x_{t}$ - value of the indicator in interval $t$;

$x_{t-1}$ - value of the indicator in interval $t-1$;

$t_{0}-$ the initial time interval;

$\log \sqrt[T]{\prod_{t=0}^{T} \frac{x_{t}}{x_{t-1}}} \cdot 100$ - logarithm of the growth rate of the indicator (average geometric of annual growth rate for the period from $t_{0}$ to $t_{T}$.

The analysis was carried out for the selection of the countries of the Center, Semi-periphery and Periphery [23]. The countries of the Center were Austria, Australia, Germany, Great Britain, Israel, France, Italy, Japan, Canada, USA, Norway, Sweden. The countries of the Semi-periphery are Brazil, Russia, India, China, Mexico, Indonesia, Turkey, Argentina, South Africa, Republic of Korea, Greece, Belgium. The countries of the Periphery are Algeria, Angola, Egypt, Ecuador, Kenya, Moldova, Sudan, Kyrgyzstan, Nigeria, Uzbekistan, Armenia, Belarus.

The following results were obtained:

a) $\sigma$-convergence of countries in terms of HDI is variable and has fluctuated throughout the analyzed period. Convergence was determined in the years 1985-1988, 19901997, 1999-2000 and further every year.

b) Based on the per capita consumption index in sample countries and the resulting static characteristics, it can be estimated that $\sigma$-convergence began to appear in 1988-2003. This process was fairly stable (held almost at the same level) in the period 1991-1999. Since 2008, according to the consumption per capita, the divergence has developed.

c) According to the data, obtained from the calculation of the H. Theil index, it can be seen, that there is not too much divergence in HDI between the countries of the center, the semi-periphery and the periphery, and this gap began to decline from approximately 2000. In the period of 1990-2000, divergence has increased, albeit insignificantly.

Verification of absolute $\beta$-convergence in terms of HDI, per capita consumption, electricity consumption per person was carried out:

a) In terms of HDI, the countries of the Center face a convergence with the rate of $4.8 \%$ per year. In Semiperipheral countries, convergence occurs at a rate of $3.017 \%$ per year. Periphery also has convergence, but at a rate of $1.9 \%$ per year.

b) In terms of per capita consumption, there is no convergence in the group of countries of the Center. In the Semi-peripheral countries, there is convergence with the rate of $0.483 \%$ per year, in the countries of the periphery there is a convergence at a rate of $0.45 \%$ per year.

c) In terms of electricity consumption per capita in the countries of the Center, there is a convergence at a rate of $0.633 \%$ per year. Convergence in the group of countries of the Semi-periphery is observed and occurs at a rather slow rate. Convergence in the countries of the Periphery in terms of electricity consumption indicator is absent.

\section{G. Sustainable development of the world economy in conditions of demographic pressure}

There was a new need - the need for such transformation of the global economy, in which production and consumption of goods are not accompanied by the growth of destructive processes, an increase in the deficit of productive resources, especially non-reproducible natural resources. The type of economy that satisfy this need began to be termed "sustainable", and the concept of "sustainable economic development" began to be actively used not only in research, but also in politics, culture, in everyday life of citizens [2428].

An analysis of the problem of demographic pressure showed that the stable and balanced development of the global economy depends on certain factors while maintaining the existing trends of demographic pressure with the horizon of forecasting to 2050 .

The first factor is the essence and content of the concept "Sustainable and balanced development of the global economy." The second factor is the nature of the social relations that have developed on the planet Earth. The third factor is the level of scientific and technological progress in the global economy and the prevailing technologies today [29], and the fourth factor is related to the provision of the economy with natural resources, including arable land.

Conclusion analysis implies that the prevailing technologies and social relations on the planet can lead humanity to an ecological catastrophe. The problem of income inequality and, as a consequence, the problem of poverty in recent times are becoming more acute. The income gap between individual population groups is increasing in each country over the last 20 years. A huge economic inequality is observed among the countries of the world. The rich get richer in all developed countries, and the incomes of the groups of the population that are found in the lower part of society in terms of their livelihoods are growing much more slowly. Convergence to the sustainable development of the global economy is not observed in conditions of demographic pressure.

\section{CONCLUSION}

Analysis of demographic pressure on nature according to the average forecast shows that by 2050 the world population will grow up to 10.065 billion people, according to the pessimistic forecast the population will reach 11 billion people, and according to the optimistic forecast 9.8 billion people. There is a need to increase production and increase the agrosphere. This cannot be done without significant 
innovation and technological development. The author came to the conclusion that currently the total world GDP is distributed extremely unevenly: $10 \%$ of the population produces an average of $62 \%$ and consumes $64 \%$, while $50 \%$ of the population of the most developing countries consume and produce about $12 \%$ of world production and consumption. The Gini coefficient of 0.57 shows an extremely uneven distribution of world GDP. If current trends in the world economy continue, there is a small probability that by 2050 it will be possible to approach the production, distribution and consumption scheme of the total world GDP, by which the Gini coefficient will tend to 0.25 .

\section{Acknowledgment}

The paper is based on the research carried out with the financial support of the grant of the Russian Science Foundation (Project No. 14-38-00009, the program-targeted management of the Russian Arctic zone development), Peter the Great St. Petersburg Polytechnic University.

\section{References}

[1] S. Liu, A. Hu, "Demographic change and economic growth: Theory and evidence from China," Economic Modelling, vol. 35, pp. 71-77, September 2013.

[2] W. A. Brown, "The past and future of growth rate estimation in demographic temporal frequency analysis: Biodemographic interpretability and the ascendance of dynamic growth models," Journal of Archaeological Science, vol. 80, pp. 96-108, April 2017

[3] W. Rougoor, C. van Marrewijk, "Demography, Growth, and Global Income Inequality," World Development, vol. 74, pp. 220-232, October 2015 .

[4] A. Mason, R. Lee, J. X. Jiang, "Demographic dividends, human capital, and saving," The Journal of the Economics of Ageing, vol. 7, pp. 106122, April 2016

[5] T. Azomahou, C. Diebolt, T. M., "Spatial persistence of demographic shocks and economic growth," Journal of Macroeconomics, vol. 31, i. 1, pp. 98-127, March 2009

[6] O.A. Rastyapina, N.V. Korosteleva, "Urban Safety Development Methods," Procedia Engineering, vol. 150, pp. 2042-2048, 2016.

[7] C. Carvalho, A. Ferrero, F. Nechio, "Demographics and real interest rates: Inspecting the mechanism," European Economic Review, vol. 88 , pp. 208-226, September 2016

[8] S. Wilson, K. C. Gil-Weir, R. G. Clark, G. J. Robertson, M. T. Bidwell, "Integrated population modeling to assess demographic variation and contributions to population growth for endangered whooping cranes," Biological Conservation, vol. 197, pp. 1-7, May 2016.

[9] W. H. Lowe, R. P. Kovach, F. W. Allendorf, "Population Genetics and Demography Unite Ecology and Evolution," Trends in Ecology \& Evolution, vol. 32, i. 2, pp. 141-152, February 2017.

[10] S. Haché, R. Cameron, M.-A. Villard, E. M. Bayne, D. A. MacLean, "Demographic response of a neotropical migrant songbird to forest management and climate change scenarios," Forest Ecology and Management, vol. 359, 1 pp. 309-320, January 2016.

[11] N. Didenko, D. Skripnuk, O. Krasulina, "Modelling the Spatial Development of the Russian Barents-Arctic Region," SGEM 2016, BK 2, vol V, pp. 471-478, Albena, Bulgaria, August 2016.
[12] P. Delacote, E. J.Z. Robinson, S. Roussel, "Deforestation, leakage and avoided deforestation policies: A spatial analysis," Resource and Energy Economics, vol. 45, pp. 192-210, August 2016.

[13] D. Z. Martini, M. A. Moreira, L. Aragão, A. R. Formaggio, E. L. DallaNora, "Potential land availability for agricultural expansion in the Brazilian Amazon," Land Use Policy, vol. 49, pp. 35-42, December 2015.

[14] H. Chen, Y. P. Zhang, "New biorefineries and sustainable agriculture: Increased food, biofuels, and ecosystem security," Renewable and Sustainable Energy Reviews, vol. 47, pp. 117-132, July 2015.

[15] R.J. Dodd, A.N. Sharpley, "Recognizing the role of soil organic phosphorus in soil fertility and water quality," Resources, Conservation and Recycling, vol. 105, part b, pp. 282-293, December 2015.

[16] L. Feng, L. Mears, C. Beaufort, J. Schulte, "Energy, economy, and environment analysis and optimization on manufacturing plant energy supply system," Energy Conversion and Management, vol. 117, pp. 454465, June 2016.

[17] Y. S. Park, G. Egilmez, M. Kucukvar, "Emergy and end-point impact assessment of agricultural and food production in the United States: A supply chain-linked Ecologically-based Life Cycle Assessment," Ecological Indicators, vol. 62, pp. 117-137, March 2016.

[18] J.-L. Fan, Y.-B. Hou, Q. Wang, C. Wang, Y.-M. Wei, "Exploring the characteristics of production-based and consumption-based carbon emissions of major economies: A multiple-dimension comparison," Applied Energy, vol. 184, pp. 790-799, December 2016.

[19] S. Bagchi, J. Svejnar, "Does wealth inequality matter for growth? The effect of billionaire wealth, income distribution, and poverty," Journal of Comparative Economics, vol. 43, i. 3, pp. 505-530, August 2015.

[20] V. Venkatasubramanian, Y. Luo, J. Sethuraman, "How much inequality in income is fair? A microeconomic game theoretic perspective," Physica A: Statistical Mechanics and its Applications, vol. 435, pp. 120138, October 2015.

[21] D. Furceri, " $\beta$ and $\sigma$-convergence: A mathematical relation of causality," Economics Letters, vol. 89, i. 2, pp. 212-215, November 2005.

[22] M. Pfaffermayr, "Conditional $\beta$ - and $\sigma$-convergence in space: A maximum likelihood approach," Regional Science and Urban Economics, vol. 39, i. 1, pp. 63-78, January 2009.

[23] T. Hoehn, 'Measuring regional income inequalities: A centre-periphery analysis of survey data," Geoforum, vol. 19, i. 4, pp. 457-465, 1988.

[24] J. Gaspar, A. Marques, J. Fuinhas, 'The traditional energy-growth nexus: A comparison between sustainable development and economic growth approaches," Ecological Indicators, vol. 75, pp. 286-296, April 2017.

[25] V. S. Tsitlenok, "About the essence and content of the category "Sustainable development of the world economy," Bulletin of Tomsk State University, vol. 4 (16), pp. 76-82, Russia, Tomsk, 2011.

[26] K. Rafika, K. Rym, S. B. Souad, L. Youcef, "A Public Actor Awareness for Sustainable Development," Procedia - Social and Behavioral Sciences, vol. 216, pp. 151-162, January 2016.

[27] R. K. Lukman, P. Glavič, A. Carpenter, P. Virtič, "Sustainable consumption and production - Research, experience, and development The Europe we want," Journal of Cleaner Production, vol. 138, part 2, pp. 139-147, December 2016.

[28] N. Kostko, D. Rudenko, A. Popkova, "Quality of life mapping for better social planning in Tyumen city, Russia," SGEM 2015, vol. 2, i. 2, pp. 1063-1070, 2015.

[29] H. Hellsmark, J. Mossberg, P. Söderholm, J. Frishammar, "Innovation system strengths and weaknesses in progressing sustainable technology: the case of Swedish biorefinery development,' Journal of Cleaner Production, vol. 131, pp. 702-715, September 2016. 